\title{
Teaching Politics in UK Universities: a survey of the profession
}

\section{Alasdair Blair, Adrian Bromage and Steven Curtis}

\begin{abstract}
In recent years one of the most significant changes in UK Universities has been the increased use of virtual learning environments (VLE) as a method of supporting learning and teaching. This has in part been influenced by research which suggests that student learning experiences can be enhanced by the judicious use of new technologies, and partly by the possibilities that the technologies help academics and students operate effectively within a system of mass higher education such has developed in the UK. Despite the fact that Politics is a discipline that has traditionally been slow to embrace new technologies (in comparison with the physical sciences), there has nevertheless been considerable interest as to the manner in which Politics is taught, including the use of VLEs. Significantly, however, this interest has been based on case studies of developments within a particular university (Lee, 2003 and Lightfoot, 2004) and there is therefore an absence of a national picture. The present paper aims to remedy this situation by reporting on the results of a questionnaire that was undertaken in September 2004 on the use of VLEs in the teaching of Politics across the UK higher education sector.
\end{abstract}

\section{Keywords}

Virtual learning environment (VLE), online learning, Politics, IT skills

\section{Context and background}

The nature and scope of teaching in UK higher education has undergone a period of dramatic change in recent years. Much of this change has been driven by external factors, such as technological developments and the influence of Government. The latter has been conscious of the need to ensure that the graduate skill base is reflective of the wider needs of the economy. In 1987, the then Department of Education and Skills (DES) noted in its White Paper 'Meeting the Challenges' that:

'there is an urgent need...for higher education to take increasing account of the economic requirements of the country' (DES, 1987).

Through the 1990s there was a dramatic expansion in student numbers against a background of a decline in the financial resources available to Universities, which in 1997 the Dearing Report had estimated had been $40 \%$ over 20 years (Dearing, 1997). There was at the same time a change in the structure of the higher education system through the abolition of the binary divide by means of the Further and Higher Education Act 1992, and the emergence of a marketplace within higher education. Universities have undergone a period of restructuring through a move towards modularisation and semesterisation, been subjected to external accountability through the teaching quality assessment reviews, and have witnessed an erosion in their funding base. When combined with the demands of the Research Assessment Exercises (RAE) and a belief that the teaching activities within Universities should reflect a range of approaches rather than the traditional lecture format, these developments have posed a number of key challenges for Universities, and more importantly, for their staff.

One of the most important aspects of these challenges has been the impact that virtual learning environments (VLE) have had on the manner by which learning and teaching has been undertaken. Although the expansion in the use of VLEs was influenced by the technological advances that dominated the $1990 \mathrm{~s}$, a common theme running through this development was the desire to improve the delivery and effectiveness of higher education. In the first instance, the issue of delivery reflected a general belief that there was a need to reassess traditional teaching techniques in the face of an expansion in student numbers, while a growing body of literature argued that students were 
being grounded in a manner of learning that avoided deep and critical reflection (Entwistle, 1992; Ramsden, 1992, p.81). Second, the notion of effectiveness pointed to an argument that graduates faced a more fluid job market that attached an emphasis to technological skills and flexibility. In other words, the acquisition of technological skills was just as important as the discipline that the graduates had chosen to study. Indeed, the Department for Education and Skills White Paper on the Future of Higher Education that was published in January 2003 specifically addressed the need for Universities to supply students with the 'skills and knowledge they need for jobs' (DfES, 2003: para 3.15). As far as graduate skills were concerned, the White Paper stressed that:

'we need to ensure that all graduates, including those that study traditional academic disciplines, have the right skills to equip them for a lifetime in a fast changing work environment' (DfES, 2003: para 3.23).

These issues were the subject of a number of important reports into higher education in the late 1990s. The most significant was the 1997 Dearing Report, which has played a major role in shaping the future direction of university education. At the same time, the 1997 Kennedy Report tackled the issue of widening participation in further education while the 1997 Fryer Report focused on the concept of a universal learning culture. Such reports were reflective of the broader agenda pursued by the 'New Labour' government, which upon taking office in 1997 sought to dramatically expand the number of students in higher education as part of a desire to create a so-called 'knowledge economy'. A key feature of this was the development of communication and information technology (C\&IT) skills, of which the Dearing Report stressed that government should:

'co-ordinate the national development ... of computer-based learning materials' and 'facilitate discussion between all relevant interest groups on promoting the development of computer-based materials and provide common units or modules, particularly for the early undergraduate years' (Dearing, 1997: recommendation 15).

Universities have responded to these pressures by adapting their approach to learning and teaching. One of the most notable developments has been the utilisation of VLEs as a means of enhancing the student learning experience through what has been referred to as e-learning. But while there has been a degree of commonality with regard to the infrastructure for developing e-learning opportunities (notably Blackboard and WebCT), there has nonetheless been a lack of commonality with regard to philosophical and pedagogical issues, and what e-learning should constitute. For example, it remains unclear whether e-learning is purely associated with distance learning, or simply with making course materials such as student handbooks available online, or is purely a means of enhancing the student experience by providing a gateway to learning materials through relevant websites. The latter moves into more profound pedagogical issues such as whether elearning should include an assessment component, or whether there should be variations in approaches between undergraduate and postgraduate provision, and more detailed questions such as whether learning resources be posted in advance of the topic under investigation or posted after the class has taken place.

Apart from the technicalities of these issues, a further series of questions has concerned the impact of e-learning on the student and staff experience. They range from broad questions as to the impact of the development of online materials on students' academic achievement to questions concerning their impact on student attendance in lectures and seminars, the amount of time that staff devote to e-learning activities and whether they consider this to be an efficient use of their time.

The research that has been conducted into these issues has yielded highly variable conclusions that, furthermore, reflect the differing views of e-learning and the range of resources that are available at individual Universities. This is a point that is emphasised in the recent HEFCE strategy on elearning, which notes that the: 
'definition of e-learning should be sufficiently broad to encompass the many uses of ICT that individual universities and colleges decide to adopt to support their learning and teaching missions. Our strategy should promote and support this diversity' (HEFCE, 2005: para.18).

In the presence of this diversity, it is nevertheless important to gain an understanding of the extent to which e-learning is actually transforming higher education. The last major survey of the teaching of Politics in UK Universities was undertaken in 1995, when the use of online materials was very much in its infancy. Yet, even that survey was able to highlight that the combination of an expansion in student numbers, the depletion of resources and the introduction of new technologies were placing heavy burdens on staff. The survey concluded that 'Politics departments were struggling to cope with increased student numbers and resource constraints, while using broadly traditional approaches to teaching and learning in terms of course delivery, assessment patterns and the development of student skills' (Stammers et al., 1999, p.124).

Some ten years later, this image of universities struggling to cope with the demands placed upon them was apparent from the consultation undertaken by HEFCE to inform its e-learning strategy that was published in 2005. That document stressed that:

'Although there has been rapid development in HE, our evidence base and responses to our consultation suggest that institutions are still struggling to "normalise" e-learning as part of higher education processes' (HEFCE, 2005: para.14).

The question remains as to whether this general picture holds true for the contemporary teaching of Politics in the UK. In an attempt to answer this question, the present paper seeks to explore the impact that VLEs have had on the teaching of Politics within UK Universities. The aim was to provide a comprehensive survey on the use of VLEs by members of the profession.

\section{Methodology}

In September 2004 a questionnaire was sent by email to all members of the Political Studies Association (PSA) who were based in UK Universities. In obtaining answers to these questions, a large-scale survey questionnaire was judged an appropriate means by which to obtain a 'bird's eye view, (Hakim, 2000: 36). In total, 1020 questionnaires were distributed, to be returned on an anonymous basis. The email addresses were obtained from the PSA member handbook which contained contact details for each member.

Central to the undertaking of the research was a desire to examine a number of themes relating to the use of online learning across politics higher education in the UK. These themes were worked into the set of questions deployed in the research. The first of these themes is the extent of use of online learning. Second, the manner by which online learning was used, for instance, purely as a means of providing core documents, such as module guides, or to provide a more interactive forum, with links to other websites and relevant resources. Third, the impact that online learning had on student attendance, participation and retention. Fourth, the extent to which different online learning strategies were employed between the teaching of undergraduate and postgraduate students.

Of the approaches taken in previously published work on the practice of politics teaching in UK universities, Stammers et al's (1999) survey adopted the following sampling method. Three questionnaires were sent to 77 Departments (one for the Head of Department and two to be completed by tutors within the Department who had been teaching Politics for three years). For Stammers and his colleagues, such an approach was deemed possible because the questionnaire was focused on the broader strategic implications of change in higher education rather than the specific reaction and or impact of individual lecturers, thus the aim was to obtain data through a select survey. However, while the survey was based on a sample which totalled 231 questionnaires, the research team had no control over the distribution of 154 questionnaires, apart from the fact that 
they should be completed by two tutors who had three years experience. For Stammers and his colleagues:

'(T)his strategy was used so that we would be able to (a) check for the possibility of systematic differences between responses from heads and tutors in the same department and (b) obtain multiple response sets from each institution in order to increase the reliability of the data collected' (Stammers et al, 1999: 117).

However, while factors relating to response rate and reliability were important motivational factors, the research was not informed by a specific methodological approach, and as a consequence, the 'representativeness' of the survey can be questioned.

Given these issues, a decision was taken in the present research to undertake a full population survey of all members of the PSA working in UK higher education institutions. It was judged that that the high degree of variance in approaches to VLE among staff would hinder the construction of an appropriate sample, in other words, any kind of sample would itself have raised questions about representativeness. This is particularly important, because the aim of quantitative research is to discover and understand underlying general patterns that occur throughout a particular population (Ragin, 1994: 131).

In terms of the actual mechanics of conducting the research, the questionnaires were administered and constructed by using specialist questionnaire authoring software, Keypoint. A questionnaire was compiled and converted to a format that allowed respondents to complete the questionnaire within the body of an email. The returned emails were retrieved by Keypoint and the raw data was automatically placed in the software's internal response database. The database has facilities to conduct cross-tabulations, select filters to enable the selection process and to export the data to Microsoft Excel. An important feature of Keypoint is that it enables a researcher to track response rates and send follow-up emails to those who have not yet submitted a survey.

\section{Participants}

The decision to construct a large-scale survey was an ambitious one. As already noted, a key issue is the accuracy of the lists to be used in constructing the questionnaire and here it was noticeable that of the 1020 questionnaires that were distributed by email, only 769 were successfully delivered. Non-delivery was influenced by such factors as staff having moved to another university, gone abroad, or their email inbox being full. Of the 769 questionnaires that were successfully delivered, a total of 71 were returned, which represented a response rate of $9.2 \%$. A direct implication of this level of response is that the survey findings might not be fully representative, which increases the potential for bias to creep into the findings and as a consequence compromise the validity of the research. At the same time, however, a low response rate such as this is not uncommon in postal and email questionnaires, particularly where no incentive has been offered, as in the present research. For example, response rates for postal questionnaires can be as low as $10 \%$ (Edwards et al, 2002). The achievement of a medium to high response rate tends to be the product of greater effort, normally through administering a questionnaire by telephone or face-to-face interview, both of which were beyond the financial and time constraints of the present research.

\section{Findings and discussion}

\section{The context of the findings}

In terms of the broad profile of the respondents, 19 (27\%) were from post-1992 Universities, 50 (70\%) were from pre-1992 Universities, while 2 respondents $(3 \%)$ did not complete this question. These broad statistics were reflective of the overall division between pre-and post-1992 Universities within the UK.

At the most basic level, respondents were asked whether or not they made use of online learning. Of the 71 respondents, 41 (58\%) made use of online learning and 30 (42\%) did not. The 41 
respondents who made use of online learning comprised 14 out of 19 respondents from post-1992 Universities and 26 out of 50 respondents from pre-1992 Universities (1 respondent did not answer the question). In contrast, of the 30 respondents who did not make use of online learning, 24 were from pre-1992 Universities and 5 were from post-1992 Universities (1 respondent did not answer the question). Possible reasons for the finding that a greater proportion of all respondents from post1992 Universities use of online learning when compared to all respondents from pre-1992 Universities could be differences in the student staff ratio, differences in institutional strategies and the amount of support available for promoting VLE use.

For those respondents who did not make use of online learning, key motivating factors were a desire to make use of hardcopy books and articles and a general concern about an impact on academic standards. These trends that are illustrated in Table 1.

Table 1: Reasons for not using VLEs

\begin{tabular}{|l|l|}
\hline Reason & 30 No responses to the use of VLEs \\
\hline Prefer to emphasise books and articles and articles and & $8(27 \%)$ \\
\hline $\begin{array}{l}\text { Prefer to emphasise books and ancerned about plagiarism } \\
\text { conces and }\end{array}$ & $3(10 \%)$ \\
\hline $\begin{array}{l}\text { Prefer to emphasise books and articles } \\
\text { concerned about academic standards }\end{array}$ & $3(10 \%)$ \\
\hline Concerned about plagiarism of online materials & $2(7 \%)$ \\
\hline Prefer face-to-face teaching & $2(7 \%)$ \\
\hline No need to because of teaching relief & $1(3 \%)$ \\
\hline Concerned about academic standards & $1(3 \%)$ \\
\hline Use other electronic sources, but not VLEs & $1(3 \%)$ \\
\hline Will make use of VLEs in the future & \\
\hline
\end{tabular}

Note: percentages reflect the ratio to the population of 30 respondents.

\section{Approaches to using VLES}

Table 2: Range of materials made available by respondents who use VLEs (41 respondents who make use of online learning)

\begin{tabular}{|l|l|l|l|l|l|}
\hline & Not at all & Sometimes & Often & $\begin{array}{l}\text { To a great } \\
\text { extent }\end{array}$ & $\begin{array}{l}\text { No } \\
\text { response }\end{array}$ \\
\hline Module guides & $4(10 \%$ & $5(12 \%)$ & $2(5 \%)$ & $30(73 \%)$ & $\mathrm{n} / \mathrm{a}$ \\
\hline $\begin{array}{l}\text { Lecture notes and } \\
\text { handouts }\end{array}$ & $3(7 \%)$ & $4(10 \%)$ & $7(17 \%)$ & $25(61 \%)$ & $2(5 \%)$ \\
\hline Online assessments & $29(71 \%)$ & $9(22 \%)$ & $2(5 \%)$ & $1(2 \%)$ & $\mathrm{n} / \mathrm{a}$ \\
\hline $\begin{array}{l}\text { Gateway to e- } \\
\text { journals or e-books }\end{array}$ & $10(24 \%)$ & $17(41 \%)$ & $8(20 \%)$ & $6(15 \%)$ & $\mathrm{n} / \mathrm{a}$ \\
\hline $\begin{array}{l}\text { Gateway to } \\
\text { appropriate websites }\end{array}$ & $5(12 \%)$ & $7(17 \%)$ & $15(37 \%)$ & $14(34 \%)$ & $\mathrm{n} / \mathrm{a}$ \\
\hline
\end{tabular}


Note: percentages reflect the ratio to the population of 41 respondents.

It is evident from Table 2 that staff are willing and able to extensively use VLEs so as to make available materials that would otherwise be accessible in printed form, such as module guides and lecture notes. The findings are similar to those of Lightfoot's (2004) study of the use of Blackboard for teaching Politics at Liverpool John Moores University, which found that of the various resources made available to students, the greatest number of students accessed lecture materials (Lightfoot, 2004: 117).

However, the use of VLEs is more than just a process of making available lecture notes and handouts (Biggs, 2003: 213-228). For subjects such as Politics, a particular attraction is the ability of VLEs to provide structured links for students to materials that are increasingly only available on the Internet. For example, government publications, materials relating to contemporary events, such as general election statistics and conflicts taking place around the world, can also be integrated into VLEs. It is clear from table 2 that staff also use VLEs as a means of directing students towards subject-specific websites, albeit not to the same extent that they provide materials that would otherwise be accessible in printed form. It can possibly be deduced that a willingness to provide module guides and lecture notes and handouts is reflective of the high demand of students for these items and the fact that they are easier for staff to make available.

VLEs also present an opportunity for Universities to ease pressure on resources - particularly library space - through electronic publications, such as academic journals and books (Stammers et al, 1999: 114). The relatively low proportions of respondents who use VLEs as gateways to ejournals or e-books may reflect either a limited availability of such materials or a lack of awareness of their availability. On the other hand, the somewhat larger proportion report using VLEs as gateways to relevant websites brings to the fore the issue of the uniqueness of such media and the potential advantages of hypermedia for certain applications.

In terms of the respondents' use of online assessment, the relatively low participation rate evidenced in Table 2 could partly be defended on the grounds that the Politics discipline, being discursive in nature, does not automatically lend itself to online assessment in the manner that Science disciplines do. Yet, in challenge to this viewpoint, VLEs do provide an opportunity for staff to develop formative assessments as a means of helping to diagnose problems in student learning, as well as to provide links to guidance regarding such issues as plagiarism and referencing skills, both of which are widely regarded as common concerns within Universities (Rosamond, 2002; Cottrell, 2003). It is possible that the findings reflect technical difficulties in setting up such assessments or a lack of training on how to do so.

\section{The impact of VLEs on the student experience}

The questionnaire also assessed when teaching materials were made available to students. Of the 41 respondents who made use of VLEs, a majority made materials available to students in advance of classes, although Table 3 shows that there was nevertheless a significant number of respondents (34\%) who made materials available to students afterwards.

An argument in favour of making materials available in advance of classes is that it provides an opportunity to move away from a passive learning environment that is often associated with lectures and tutorials, and instead to promote an active and student-centred learning environment (see Denicolo, Entwistle and Hounsell, 1992; Surry, 2000). Reflecting on her own experience of using Nicenet at Nottingham University, Lee (2003: 68) found that placing full lecture notes on the internet classroom a day or two before the lecture meant that there: 
"was not need for the "tipper-truck approach" to the lecture and was a way of avoiding the "note-taking trap" of concentrating on getting things down rather than understanding what is being discussed' (Lee, 2003: 68).

One implication of this strategy is that lectures tend to become structured around short presentations followed by the setting of tasks for students and the opportunity for discussion.

Table 3: Approaches to making materials available online

(41 respondents who make use of online learning)

\begin{tabular}{|l|l|}
\hline Availability of materials & Responses \\
\hline Well in advance of the class & $14(34 \%)$ \\
\hline Immediately before the class & $8(20 \%)$ \\
\hline Immediately after the class & $11(27 \%)$ \\
\hline Sometime after the class & $3(7 \%)$ \\
\hline No response & $5(12 \%)$ \\
\hline
\end{tabular}

Note: percentages reflect the ratio to the population of 41 respondents.

The idea is that interactive windows in lectures support active learning (). By taking this approach the role of lecturer often changes to that of supporting learning rather than 'being the fount of all knowledge relevant to a module' (Haynes and Anagnostopoulou, 2002: 62). In this sense:

'teaching is less about what the teacher does (i.e. signs of teaching) and more about what the students do in relation to the teaching (i.e. what is signified by the teaching)' (Prosser and Trigwell, 1997 cited in Stiles and Orsmond, 2002: 54).

Such viewpoints reflect widely held criticisms of the traditional lecture as a format which emphasises passive and dependent learning (Ramsden, 1992: 153-156). It has been stressed that there is often a low degree of linkage between the information conveyed in lectures and what students learn, as the majority of learning takes place outside of the classroom. It has been argued that VLEs offer one means of tackling this problem, with a more active learning environment whereby students are encouraged to take on responsibility for their own learning (Boud, 1988). A central feature of Boud's argument is that VLEs do not replace the need for seminars and lectures, but rather, give the opportunity to refocus the manner by which lectures and seminars have traditionally operated.

Some academics' reticence to use VLEs is grounded in a concern that students will view seminars and lectures as being less necessary. These views are, however, in contradistinction to the evidence obtained from those respondents who made use of online learning. It is shown in Table 4 that when asked to consider the impact that online learning had on lecture and seminar attendance, $15 \%$ considered that there had been an increase in attendance. However, the majority of respondents (56\%) noticed no notable change, while $27 \%$ believed that attendance had somewhat decreased.

These findings partly support the conclusions of other studies concerning the impact of VLEs on Politics teaching. For example, Simon Lightfoot, reflecting on his experience of using Blackboard noted that there was a drop in student attendance, although the feedback received from his study left him uncertain as to whether this was a product of online learning or a result of other factors 
(Lightfoot, 2004: 177). And while Donna Lee similarly recorded a drop in student attendance, particularly around the time of essays and exams, she also rightly noted that a percentage of students will miss classes no matter the teaching method used (Lee, 2003: 69).

Table 4: Impact of VLE on attendance at lectures and seminars

(41 respondents who make use of online learning)

\begin{tabular}{|l|l|}
\hline Attendance at lectures and seminars & Response rate \\
\hline Greatly reduced attendance & $\mathrm{n} / \mathrm{a}$ \\
\hline Somewhat reduced attendance & $11(27 \%)$ \\
\hline No noticeable difference & $23(56 \%)$ \\
\hline Somewhat increased attendance & $6(15 \%)$ \\
\hline Greatly increased attendance & $\mathrm{n} / \mathrm{a}$ \\
\hline No response & $1(2 \%)$ \\
\hline
\end{tabular}

Note: percentages reflect the ratio to the population of 41 respondents.

When participation in classes and seminars is considered, table 5 shows that $49 \%$ considered that there was no notable difference in participation, $37 \%$ thought participation had slightly improved and $7 \%$ that it had greatly improved. By contrast, only $7 \%$ believed that participation had slightly been reduced. It can therefore be deduced from the findings with regard to attendance and participation that VLEs contribute to, rather than work against, the fostering of an active learning strategy.

Table 5: Impact of VLE on participation in seminars and classes

(41 respondents who make use of online learning)

\begin{tabular}{|l|l|}
\hline Participation in seminars and classes & Response rate \\
\hline Greatly reduced participation & $\mathrm{n} / \mathrm{a}$ \\
\hline Slightly reduced participation & $3(7 \%)$ \\
\hline No noticeable difference & $20(49 \%)$ \\
\hline Slightly improved participation & $15(37 \%)$ \\
\hline Greatly improved participation & $3(7 \%)$ \\
\hline
\end{tabular}

Note: percentages reflect the ratio to the population of 41 respondents.

Apart from the specific impact that VLEs have on participation and attendance rates, they are commonly regarded as an important means of enhancing the overall student experience. This includes helping to improve communication with students by means of responding to their enquiries, an increasingly important consideration, given the fact greater diversification in the student body (mature, full-time, part-time, distance-learning) often means that students are unable to attend university on a sufficiently regular basis for face-to-face meetings. Table 6 shows that a minority of the respondents (5\%) purely saw the value of VLEs as a communication tool to assist 
with responding to student enquiries. Instead, the majority of respondents regarded the VLEs to be of value in both enhancing the student learning experience as well as communication vehicle.

Table 6: Impact of VLE on student experience

(41 respondents who make use of online learning)

\begin{tabular}{|l|l|}
\hline Nature of Impact & Responses \\
\hline Responding to students queries & $2(5 \%)$ \\
\hline Enhancing students learning experiences & $10(24 \%)$ \\
\hline $\begin{array}{l}\text { Responding to students queries and enhancing } \\
\text { students learning experiences }\end{array}$ & $18(44 \%)$ \\
\hline No response & $11(27 \%)$ \\
\hline
\end{tabular}

Note: percentages reflect the ratio to the population of 41 respondents.

\section{Approaches to VLEs for undergraduate and postgraduate students}

The evidence presented so far highlights that those staff making use of VLEs for the most part consider it to be beneficial to the student learning experience, and there is a greater tendency to provide resources such as lecture notes and module handbooks. For those respondents who did not make use of online learning, it seems that one of the main motivating factors was a concern that VLEs undermined rather than supported the student learning experience, or at least their own perceptions of the ideal student learning experience.

It was with this in mind that the questionnaire also asked respondents to consider whether they varied their use of online learning between undergraduate and postgraduate students. This question was motivated by the assumption that the more guided independent learning that is associated with postgraduate study - namely less use of lectures - would mean that resources such as lecture guides would be less suitable.

Of the 41 respondents who made use of online learning, $21(51 \%)$ said that they did not vary their use of online learning at higher levels of study, while 17 (42\%) said they did so (3 (7\%) did not provide an answer). For those respondents who varied their use of online learning, Table 7 shows that such a strategy was indeed borne out of a desire to tailor their approach to the needs of postgraduate students.

Table 7: Reasons for varying approach to VLEs at postgraduate level (17 respondents varied their approach)

\begin{tabular}{|l|l|}
\hline Method of variance & Responses \\
\hline Greater emphasis on printed materials & 7 \\
\hline Less emphasis on module materials & 1 \\
\hline More online exercises & 3 \\
\hline $\begin{array}{l}\text { Greater emphasis on printed materials and less emphasis on } \\
\text { module materials }\end{array}$ & 2 \\
\hline $\begin{array}{l}\text { Use for different purposes - overall course information, specific } \\
\text { workshops and scenarios }\end{array}$ & 1 \\
\hline Make options available for seminar groups to develop their own & 1 \\
\hline
\end{tabular}




\begin{tabular}{|l|l|}
\hline materials & \\
\hline More new papers in academic journals & 1 \\
\hline Workshops in the use of databases & 1 \\
\hline
\end{tabular}

Note: percentages reflect the ratio to the population of 17 respondents.

\section{Concluding reflections}

The findings that have been presented in this article provide a general overview of the use of VLEs in the teaching of Politics. They highlight the fact that the use of VLEs is far from harmonised across Politics teaching in the higher education sector. However, the low response rate to the questionnaire means that the findings are unable to present a definitive account. Despite the limitations of the research, some general patterns are evident, including the tendency to make use VLEs as a means of distributing module guides and lecture notes/handouts rather than as a vehicle for conducting online assessments.

Moving to a more detailed analysis, the evidence that has been presented in this article contradicts critics of VLEs who argue that they might undermine face-to-face teaching and diminish attendance at lectures and seminars. Indeed, a number of the respondents considered that lecture and seminar attendance had actually increased when using VLEs. The evidence for class participation is even clearer, with a significant number of respondents (44\%) considering that participation had improved.

The present research provides evidence that politics educators find that there is value in the use of VLEs. However, it is apparent that a fuller picture of the use of VLEs in the teaching of Politics can only be obtained from a survey which produces a higher response rate. To do so would require measures such as, for example, incentives to participate and chasing of responses by telephone, and they would need to be costed into the project.

\section{Note}

Thanks to the editors and reviewers of this journal for their helpful comments, to the staff at the Centre for the Study of Higher Education at Coventry University, and to the support of the Higher Education Academy Subject Network for Sociology, Anthropology and Politics.

\section{References}

Biggs, J. (2003), Teaching for Quality Learning at University, Buckingham: Society for Research into Higher Education.

Boud, D. (ed.) (1988), Developing Student Autonomy in Learning, $2^{\text {nd }}$ ed., London: Kogan Page.

Cottrell, S. (2003), The Study Skills Handbook, Basingstoke: Palgrave.

Dearing, Lord (1997), 'The Dearing Report', London: HMSO.

DES (Department of Education and Science) (1987) Meeting the Challenge, London: HMSO, Cmnd 114.

Denicolo, P., Entwistle, N. and Hounsell, D. (1992), What is Active Learning?, Sheffield: CVCP Universities Staff Development and Training Unit.

DfES (Department for Education and Skills) (2003), The Future of Higher Education, London: HMSO, Cmnd 5735.

Edwards, P., Roberts, I., Clarke, M., DiGuiseppi, C., Pratap, S., Wentz, R., and Kwan I. (2002), 'Increasing response to postal questionnaires: systematic review', British Medical Journal, 324, 18 May, pp.1183-5.

Entwistle, N. (1992), The Impact of Teaching on Learning Outcomes - A Literature Review, Sheffield: Universities Staff Development Unit. 
OK, just delete this.Hakim, C. (2000), Research Design: Strategies and Choices in the Design of Social Research, $2^{\text {nd }}$ edn, London: Routledge.

Haynes, M. and Anagnostopoulou, K. (2002), 'Virtual learning environments as tools in learning and teaching,, in S. Fallows and R. Bhanot, R. (eds) Educational Development through Information and Communications Technology, London: Kogan Page, pp. 59-71.

HEFCE (Higher Education Funding Council for England) (2005) HEFCE Strategy for E-learning, March.

OK, just delete this.Lee, D. (2003), 'New technologies in the Politics classroom: Using internet classrooms to support teaching and learning', Politics, 23: 1, pp. 66-73.

Lightfoot, S. (2004), 'Can Blackboard help support Politics students?', LATISS - Learning and Teaching in the Social Sciences, 1: 3, pp.169-180.

OK, just delete this.Prosser, M. and Trigwell, K. (1997), 'Relation between perceptions of the teaching environment and approaches to teaching', British Journal of Educational Psychology, 67, pp.35-35.

Ragin, C. (1994), Constructing Social Research: The Unity and Diversity of Method, Thousand Oaks CA: Pine Forge Press.

Ramsden, P. (1992), Learning to Teach in Higher Education, London: Routledge.

Rosamond, B. (2002), 'Plagiarism, academic norms and the governance of the profession', Politics, 22: 3, pp.167-74.

OK, just delete this.Stammers, N., Dittmar, H. and Henney, J. (1999), 'Teaching and Learning Politics: A survey of practices and change in UK Universities', Political Studies, 47: 1, pp. 114126.

Stiles, M. and Orsmond, P. (2002), 'Managing active student learning with a virtual learning environment', in S. Fallows and R. Bhanot, R. (eds) Educational Development through Information and Communications Technology, London: Kogan Page, pp. 45-58.

Surry, D.W. (2000), 'Strategies for motivating higher education faculty to use technology', Innovations in Education and Training International, 37: 2, pp. 245-254.

\section{Contributor details}

Alasdair Blair (please add 2 or 3 biographical sentences) Alasdair Blair is Jean Monnet Professor of International Relations at Coventry University. In addition to his research interests in British foreign policy and European integration he is involved in the The Scholarship of Engagement for Politics FDTL project with colleagues at the University of Warwick and Oxford Brookes University. In 2006 he was awarded a National Teaching Fellowship.Contact: Department of International Studies and Social Science, Faculty of Business, Environment and Society, George Eliot Building, Coventry University, Priory Street, Coventry, CV1 5FB, UK

Email: a.blair@ coventry.ac.uk

Adrian Bromage (please add 2 or 3 biographical sentences) Adrian Bromage is a Pedagogic Researcher in the Coventry University Centre for the Study of Higher Education and provides research support and webpages for the iPED Research Network. Adrian's interests include ontological and epistemological questions regarding virtual reality.

Contact: Centre for the Study of Higher Education, Coventry University, Priory Street, Coventry, CV1 5FB, UK

Email: a.bromage@ coventry.ac.uk

Steven Curtis (please add 2 or 3 biographical sentences)

Steven Curtis teaches International Relations at Coventry University and is a Research Fellow on The Scholarship of Engagement for Politics FDTL project which explores the use of placements in the teaching and learning of Politics and International Relations.

Contact: Department of International Studies and Social Science, Faculty of Business, Environment and Society, George Eliot Building, Coventry University, Priory Street, Coventry, CV1 5FB, UK 
Email: s.curtis@ coventry.ac.uk 